\title{
Is there more violence around schools? Four tests across nine cities
}

\section{P J Ashby}

Received: date / Accepted: date

\section{JOURNAL ARTICLE PRE PRINT}

This is the version of this article submitted to a journal for publication. It has not yet been peer reviewed. It may vary from the final published version.

Abstract Objectives: Research evidence on schools as a factor in the distribution of neighborhood violence has produced varying and at-times directly contradictory results. Drawing conclusions from existing research is also complicated by data limitations and methodological differences. The present study sought to further research in this area using a novel open-data source.

Methods: Police-recorded assault and personal robbery data from nine large US cities were used to test four hypotheses (derived from the routine activities approach) on spatio-temporal patterns of violence around schools. Multi-level Markov Chain Monte Carlo models were used to reflect the clustered structure of the data.

Results: The presence of a public secondary (middle or high) school in a census block group was associated with higher daytime assault and robbery counts on weekdays when schools were in session but not on non-school weekdays, and the effect was larger for larger schools. No such relationships were found for elementary schools. However, there were variations between cities, in that there was no effect in one city and the effect sizes in other cities varied substantially.

Conclusions: The results were consistent with the routine activites approach, suggesting a role for middle and high schools in the distribution of neighbourhood violence. The differences between cities suggest that studying multiple cities is important in the investigation of crime and place, and that

Address(es) of author(s) should be given 
open data may provide a mechanism for overcoming the data-access difficulties that have previously limited multi-city studies of spatio-temporal variations in crime.

Keywords crime $\cdot$ schools $\cdot$ routine activities $\cdot$ open data

\section{Introduction}

The problems of violence against, and by, young people are long established and of substantial public and policy concern. Non-fatal assaults on 10-19 year olds are estimated to lead to over 300,000 emergency-room visits each year in the United States, with associated medical and work-loss costs of approximately $\$ 2$ billion (Centers for Disease Control and Prevention 2014).

Like other types of crime, violence is heavily concentrated in both space and time. One driver of the concentration of violence is the patterns of land use that influence the everyday activities of potential victims and offenders (Stucky and Ottensmann 2009). In the case of violence involving young people, schools may be a particularly relevant land use. However, existing research in this area presents a confusing picture, with different studies having produced sometimes directly contradictory results. Since all previous studies have been based on datasets from single cities, it is not possible to know if these differing results are the result of genuine differences in the relationship between schools and violence in different cities, or are artifacts of the varying methods used in previous studies.

This study uses a novel dataset to contribute to research on violence around schools in three ways. Firstly, it uses crime data from nine different cities to analyse not only the nature of relationships between schools and violence but the consistency of such relationships across cities. Secondly, it uses withinsubjects designs to control for unmeasurable factors that may confound any relationship between schools and neighborhood violence. Thirdly, it tests multiple theoretically driven hypotheses to explore the mechanisms underlying and relationships between schools and violence.

\section{Background}

Relationships between places and crime are often understood using the routine activities framework, first outlined by Cohen and Felson (1979) and subsequently developed by various scholars (for an outline of the developed theory, see Eck and Madensen 2015). This approach conceptualizes crime as the product of interactions between offenders and targets at places, mediated by the actions of controllers (target guardians, place managers and offender handlers) who in some circumstances can prevent such interactions. 
The routine activities approach is particularly useful for analyzing relationships between crimes, places and people's activities. A neighborhood containing a school, compared to an otherwise identical neighborhood without any schools, may have interactions between people and places that are relevant to violent crime in several ways. Most obviously, a school will concentrate schoolage children into the surrounding area immediately before and after school hours, and potentially during the school day, providing both a possible pool of offenders and of targets for violence. A school may also increase the number of potential guardians against crime in an area, in the form of school staff, bus drivers and parents. The presence of these people may also have second-order effects, for example if a fast-food restaurant opens near a school (Austin et al. 2005) to be near its customer base and the restaurant itself then generates new opportunities for violence.

The ways in which schools may influence interaction between offenders, targets and controllers may vary at multiple levels. Differences between schools may result from school policies and practices (through which schools can exercise management of places, handling of offenders and guardianship of targets) or the other types of land use present in the surrounding area. There may also be variations between schools in different cities, again as a result of variations in policy but also as a consequence of the substantial differences between the types of environment found in, for example, San Francisco and Detroit.

Studies that use data from one city inherently cannot identify between-city differences. This limits their usefulness, particularly for practitioners who are unlikely to be able to assess the relevance of published results to the city in which they work. This limitation of single-city studies is particularly important because of the infrequency of replication studies in criminology relative to some other disciplines (Pridemore, Makel, and Plucker 2018). This leads to a situation where those wanting to base decisions on research findings must rely on a small number of studies that are not necessarily comparable with one another. Analyzing data from multiple cities in a single study does not address all of the problems replication studies can deal with, but can lead to a better understanding of the generalizability of relationships between crime and place.

\section{Existing literature}

Previous studies that have investigated relationships between schools and violent crime are summarized in Table 1. All have used data from the United States, with each studying a single city except Roman (2003), who studied a suburban county outside Washington, DC.

These studies have generally shown that the frequency of assaults is higher in city blocks with or immediately adjacent to public high schools, although Stucky and Ottensmann (2009) found no effect. Beyond that, results have been more mixed. Roncek and Faggiani (1985) and Roman (2003) found blocks with private high schools had more assaults than those with no schools, while Ron- 
cek and Lobosco (1983) and Roncek (2000) found that relationship was unique to public high schools. Similarly, Roncek and Faggiani (1985) and Haberman and Ratcliffe (2015) found robbery counts were higher around high schools, while Stucky and Ottensmann (2009) and Willits, Broidy, and Denman (2013) found no effect.

Effect sizes also varied substantially across studies. Few authors reported this information directly, but it may be beneficial to compare effects, even if approximately. Five of the studies listed in Table 1 reported sufficient information for the calculation of effect sizes in the form of odds ratios (see Appendix). The size of apparent effects varied substantially, with the presence of a high school on a block being associated with odds ratios from 1.05 (Murray and Swatt 2013) to 2.07 (Haberman and Ratcliffe 2015), corresponding to percentage changes in assaults of $5 \%$ and $107 \%$ respectively. These very different effect sizes across cities suggest further work is necessary to understand the generalizability of relationships between schools and violence.

Notable for the routine activities explanation of violence around schools are the results of two studies that analysed how such violence varies by time of day. Consistent with the explanation that schools alter the frequency of violence by influencing people's routine activities, Roman (2003) found that assaults around schools were only higher during times when schools were open. Conversely, Haberman and Ratcliffe (2015) found that high schools were associated with more robberies both during school times and overnight when schools were closed.

There are at least two potential explanations for these partially conflicting results. They may reflect genuine differences in relationships between schools and violence between cities, or they may be a consequence of methodological differences (and in some cases shortcomings) between studies. For example, previous studies have attempted to control for differences between neighborhoods by including socio-economic measures known to be correlated with crime, but each study has done this in a different way. Some previous research used regression models that appear to be inappropriate for the data under study. For example, Roncek and Lobosco (1983), Roncek and Faggiani (1985) and Murray and Swatt (2013) all used ordinary least-squares regression, despite crime counts (the dependent variable in each case) almost-always violating the assumption of normality required for such models to be valid. Similarly, Roncek and Lobosco (1983), Roncek and Faggiani (1985) and Roncek (2000) did not control for spatial auto-correlation, without which models may be vulnerable to omitted variable bias (Anselin and Griffith 1988). It is not known, however, what influence these limitations may have had on the corresponding results.

In summary, the existing research suggests public high schools are associated with a higher number of assaults, but that relationships for other types of school, and between robberies and all school types, are unclear. Even for assaults around public high schools, there is substantial variation in effect size. In light of the methodological differences described in this section, it is difficult to know whether the differences in previous results reflect genuine differences 
between cities or artifacts of the research process. This limits the usefulness of those results for both researchers and practitioners working to reduce youth violence. As described in the following sections, the present study attempted to better understand the relationships between schools and local violence together with variations in those relationships between cities.

\section{Hypotheses}

The present study used the routine activities approach to generate four hypotheses that could be tested to explore whether schools are associated with variations in violent crime. In each case, these hypotheses were tested across multiple cities to understand variations in the observed relationships and to improve the generalizability of the results.

H1: the presence of a school will predict higher daytime violent crime counts during school hours on weekdays on which schools are in session than on weekdays on which schools are closed.

If schools increase violence in surrounding areas because they influence the routine activities of students and others, it would be expected that such an effect would be greatest when schools were open. This hypothesis does not predict the absence of any association when schools are closed, since some school facilities may be used for other activities.

Implicit in this hypothesis is a within-subjects design in which violence is measured repeatedly for each area on days on which schools are in session and those on which they are closed. Since it is likely that there will also be variations between daytime and night-time offenses, and between weekdays and weekends, offenses occurring at any time on weekends or on weekdays before 07:00 or after 18:59 hours were excluded. This design allows this study to control for differences between areas with schools and areas without, even if those differences are unknown or cannot feasibly be modeled.

H2: the presence of a secondary (middle and high) school will predict higher violent crime counts in the surrounding area but an elementary school will not.

Children who offend typically do so most-commonly during their teen years, with very few beginning to offend before they leave elementary school (Bacon, Paternoster, and Brame 2009). Victimization risk for violent crime outside the home similarly peaks in late teenage years (Harrell 2012). Consequently, if schools influence crime in surrounding areas through the activities of students, it appears likely that this influence will operate for schools educating teens rather than younger children. Middle and high schools are grouped together in this hypothesis because the age at which students move to high school varies slightly both between and within cities. 
H3: the presence of a secondary school will predict higher daytime counts of violent crimes on school days in public places than in private places.

If schools influence the occurrence of violence by influencing the routine activities of students, it might be expected that they would do so only in places to which students have access. So, for example, a school creating concentrations of students in nearby malls, fast-food restaurants and streets might be expected to influence violence there, but would not be expected to have the same influence on violence in dwellings.

H4: given that there is at least one school in an area, larger numbers of secondary-school students educated in the area will predict higher daytime counts of violent crimes on school days but larger numbers of elementary-school students will not.

If the routine activities of students and others provide the mechanism for any relationship between schools and crime, it would be expected that the activities of a larger number of students would be associated with a larger effect. This is important to study because some schools are so much larger than others. In the cities under study, the size of schools varied from a handful of students to over 5,000 .

Some previous studies of violence around schools have found that public schools are associated with more crime while private schools are not (see Table 1). To control for this potential difference, in testing each hypothesis a distinction was made between public and private schools. H4, however, could only be tested for public schools because only a small number of block groups containing schools contained private schools.

\section{Data}

Crime data were obtained from the Crime Open Database (Ashby 2018). This database contains open crime data from large US cities that has been harmonized into a common format to allow simultaneous analysis of data from multiple cities. Data were available for nine of the 50 largest US cities (Chicago, Detroit, Kansas City, Los Angeles, Louisville, New York, San Francisco, Tucson and Virginia Beach) for the five calendar years 2013 to 2017. This dataset included records of 478,505 assaults and 62, 457 personal robberies. Each record included approximate geographic co-ordinates for the offense along with the date and time at which it occurred. Records from four cities (Chicago, Los Angeles, Louisville and New York) also included the type of location in which the offense occurred.

To protect the privacy of crime victims, cities releasing open data typically obfuscate the locations of crimes by either introducing small inaccuracies into geographic co-ordinates or recording all offenses as occurring at the centroid of the nearest street segment. Whether this is problematic for criminological research depends on the chosen spatial scale of analysis. The obfuscation process 
means open data are not suitable for analysis of crime concentrations between addresses or within street segments, while analysis at larger scales (such as census blocks) is unlikely to be affected (for further discussion, see Ashby 2018). Tompson et al. (2014) found that open data that had been spatially obfuscated in a similar manner were sufficiently accurate for use in spatial analysis using counts of crimes in areal units.

The choice of a unit of analysis in this study was determined by a separate issue inherent in police data. In many cases, the people reporting crimes to the police may not report the offense location exactly. For example, a victim may report that they were robbed on a small residential street outside a particular address, while another victim reporting an offense at the exact same location may describe it as having happened outside the address next door. A recent study by Gerell (2018) found a median difference of 83 meters between police and fire department records of the locations of the same arson incidents.

Previous studies of violence around schools have typically compared the frequency of crime in census blocks containing schools with that in blocks without schools. However, in Figure 1, a crime occurring at point 'A' could be recorded as either occurring in a census block with or without a school, since the block boundary follows the street center line. Combined with inaccuracy in reporting, this could lead to crimes being counted in a different census block to the one in which they occurred.

Comparing census blocks with and without schools to understand crime around schools is also potentially problematic because schools themselves often take up most or all of a block. In Figure 1, for example, the highlighted elementary school takes up almost all of the census block within which it sits. Using the block containing this school to represent the area around the school fails to capture almost all of the local environment, even properties that are directly adjacent to the school campus.

To avoid this problem, the present study used census block groups as the unit of analysis. Block groups are created by combining census blocks into larger units. Block group boundaries are reviewed by local government bodies as part of the US Census Bureau Participant Statistical Areas Program to ensure they are meaningful representations of local areas (US Census Bureau 2008). The block groups shown in Figure 1 demonstrate that they may be a more-appropriate spatial unit for assessing violence around schools than the census blocks used in previous studies. Using block groups also allows for use of demographic estimates derived from the American Community Survey (ACS), which are not published for census blocks.

Schools are not placed at random within cities but sited where they are needed. In comparing violence in block groups with and without schools, it is therefore necessary to control for other potential differences between areas. In common with some (but not all) previous studies, the present study attempted to control for socio-economic variables that are known to be relevant to the distribution of crime. Specifically, residential population and separate indices of concentrated disadvantage, residential mobility and ethnic heterogeneity were calculated in the same way as described by Haberman and Ratcliffe (2015). In 
addition, since schools are likely to be built in areas with many school-aged children, the proportion of the population aged 13-19 was included. Since street crime is known to be associated with many types of non-residential land use (Wilcox and Eck 2011), the proportion of each block group zoned for commercial use was obtained from the open data website of each city government. All other demographic data were derived from 2016 five-year ACS estimates. Summary statistics are shown in Table 2.

School data were obtained from the US Department of Education. Data on public schools is contained in the Common Core of Data (National Center for Education Statistics 2016a), with the corresponding data for private schools contained in the Private School Universe Survey (National Center for Education Statistics 2016b). In both cases, data from the 2015-16 school year was used. Schools only offering only kindergarten or prekindergarten, that were shown in the data as being closed or future schools, schools based in dwellings and schools recorded as having fewer than 10 students were excluded. Counts of schools and students were then made at the block group level, as summarized in Table 3.

The dates on which schools in each city were in session were obtained from the Teacher Contract Database (National Council on Teacher Quality 2018), which includes school calendars for many large school districts. This database records scheduled school days, so cannot reflect unexpected closures for extreme weather or other events. Private schools were assumed to follow the calendars of public schools in the same city for the convenience of parents with children at different schools, although it is likely that there remains some variation in school sessions that could not be captured in the models presented here.

\section{Methods}

Analysis of crime count data typically uses negative binomial regression models, since crime counts are non-negative and are usually over-dispersed. The present study required two modifications to this approach. Firstly, the use of data from multiple cities and the repeated measurement of crime counts in each block group introduced clustering into the data. This required the use of mixed-effects (hierarchical) models. Secondly, the size of the dataset (two measurements for each of 12,919 block groups) meant that mixed-effects maximum-likelihood regression approaches to fitting the models were not computationally feasible.

To study the data given these constraints, a Bayesian Markov Chain Monte Carlo (MCMC) generalized linear mixed model (GLMM) was used. Similar models have only occasionally been used to study relationships between crime and place, and then by scholars from outside criminology such as Cunradi et al. (2011), Gracia et al. (2015), Li et al. (2014), Sparks (2011) and Zhu, Gorman, and Horel (2006). MCMC models have, however, been used in life-course criminology (e.g. Telesca et al. 2012) and the study of criminal networks (e.g. 
Young 2011). For a discussion of other uses of MCMC models in criminology, see Law, Quick, and Chan (2014).

Counts of violent crimes in block groups were Poisson distributed, as expected. Unlike in Poisson regression, the MCMC GLMM model used here accounts for over-dispersion (Hadfield 2010). As a Bayesian approach, MCMC models require the specification of priors for each of the predictors. In the absence of knowledge of the magnitude of relationships between the predictors and violence counts, particularly given the potential for them to vary across cities, weakly informative priors were specified. Since continuous predictors had been centered and scaled (see below), for each parameter a prior was specified with zero as the mean and an arbitrarily large variance, allowing the model to estimate any value. 50, 000 iterations of each model were run, with the first $10 \%$ discarded (the 'burn-in' period) and every 20th iteration after that retained for inference to reduce auto-correlation. Model convergence was assessed using the test outlined by Gelman and Rubin (1992), with a value of $R$ lower than the maximum acceptable value of 1.05 in each case, indicating the models had successfully converged. Trace plots of the parameters were inspected and found to be stationary, confirming that the values had stabilized before the end of the burn-in period.

Data analysis was conducted in $\mathrm{R}$ version 3.5 (R Core Team 2018), with 2016 census boundaries from the tigris package (Walker 2018b) and ACS data from the tidycensus package (Walker 2018a). Modelling was done using version 2.26 of the MCMCglmm package (Hadfield 2010), with model comparison using version 1.42 of the MuMIn package (Bartoń 2018) and model convergence using version 0.19 of the coda package (Plummer et al. 2006).

Crime counts are typically spatially auto-correlated (Chainey and Ratcliffe 2005). To account for this, a spatial lag term was included as a predictor. The lag for each block group was calculated as the mean of the crime counts of the adjacent block groups (using 'Queen' contiguity). Since spatial autocorrelation could vary across crime types, time periods and location types, separate lags were calculated for assault and robbery for each period and type.

Total population, the proportion of residents who are teens and the numbers of students attending schools in the area were all scaled by dividing each value by the standard deviation of values and centered by subtracting the mean value from each value. The number of students in each block group was scaled, but not centered. Scaling and centering was done separately for data from each city, so a scaled and centered value of zero in a block group is equal to the mean value for block groups in that city.

\section{Results}

As a Bayesian approach, MCMC models do not produce overall model significance statistics, with inference instead being by comparison of alternative models using a measure such as the deviance information criterion (DIC) out- 
lined by Spiegelhalter et al. (2002). In the present study, the 'full' model used to test each hypothesis was compared with two alternatives. The first ('empty') model described the structure of the data by including a dummy for each repeated measure in each city, but no other predictors. This is analogous to an intercept-only model in non-hierarchical modelling. The second ('control') model added the socio-economic variables to the empty model. The DICs of these models were compared against the full model for each hypothesis using the model.sel () function in the MuMIn R package. In each case this showed the full model including the school variables was more likely given the data than the corresponding control model containing only socio-economic variables or the empty model containing only the repeated measures and city structures of the data. As such, the school variables can be said to have value in predicting the frequency of violence at the block group level.

Each model includes estimates of the value of each variable for each city at each time period, up to 182 for each model. For reasons of space, mean estimates and their standard deviations are shown in the online supplementary material, with the results summarized graphically in the figures referenced below.

\subsection{Hypotheses 1 and 2}

MCMC models produce a distribution of estimates for each parameter $(2,250$ estimates each in the models presented here), referred to in Bayesian terms as the posterior distribution of the parameter. Figure 2 shows the posterior distribution of each school-related parameter in the model used to test H1 and $\mathrm{H} 2$ for assaults, with the median estimate marked with a vertical line. The width of each distribution corresponds to the uncertainty of the estimate: the wider the distribution, the less certain the value. This can be seen in the estimates for private schools in Detroit: there are relatively few private schools, leading to small sample sizes and uncertain estimates. Conversely, New York has many schools and many block groups, leading to less uncertainty in the model estimates.

The horizontal axis of each panel shows the values of the estimates, presented as odds ratios, i.e. $e^{\text {estimate }}$. Estimates can therefore be interpreted as the modeled ratio of assault frequency in a given block group relative to that in a block group that does not contain any schools. The difference between the relative horizontal positions of the estimates within each panel can be interpreted as the magnitude of any difference between the modeled frequency of assaults in block groups with schools during different time periods. Where the estimates within a panel are aligned directly above one another, there is little difference in the modeled frequency of assaults over time.

The differences in odds ratios between time periods are quantified by estimating the probability that the true value of the parameter for assaults on school days is greater than the value of the parameter on non-school days. This probability was estimated by simulation, with 1,000 samples (with re- 
placement) from the posterior distribution for school days compared with the same number from the posterior distribution for non-school days. The proportion of samples for which the size of the effect for school days is greater than that for non-school days is shown as a percentage (in italics) at the bottom of each panel in Figure 2.

The first two columns of Figure 2 show estimates for elementary schools. All the values are close to and appear randomly distributed around 1, the odds ratio corresponding to no effect. The mean probability of the estimate for school days being greater than that for non-school days is $44 \%$ for private elementaries and $54 \%$ for public elementaries, very close to the value of $50 \%$ that would be expected to occur by chance if the two distributions were identical. This suggests that elementary schools are not consistently associated with any variation in the frequency of assaults, whether on school days or not.

The third column of Figure 2 shows corresponding estimates for private secondary (i.e. middle and high) schools. In most cities the expected frequency of assaults does not vary either between block groups with and without such schools (the magnitude of the odds ratios), or between time periods in block groups with schools (the relative horizontal positions of the density curves within each panel). The mean probability of the odds ratio for school days being greater than the odds ratio for non-school days is only $61 \%$, similar to the probabilities for elementary schools. This suggests no consistent relationship between private secondary schools and assaults in those cities. The two exceptions are Kansas City and Virginia Beach, where the expected frequency of assaults is higher in block groups with private secondary schools during the daytime on days when schools are in session, both compared to block groups without schools and compared to non-school days in block groups with such schools.

The final column of Figure 2 shows the results for public secondary schools. For each city, there is a greater than $90 \%$ probability that the odds ratios for daytime assaults on school days is higher than on non-school days and higher than in block groups without schools. The magnitude of this effect varies across cities, with an odds ratio of 2.55 in San Francisco but a ratio of only 1.35 in Louisville. Overall, Figure 2 shows support for both $\mathrm{H} 1$ and $\mathrm{H} 2$ in relation to assaults, but (except in two cities) only for public schools.

Figure 3 shows the corresponding results for the frequency of personal robbery. For elementary schools and private secondary schools, these results broadly match those found for assaults: there appears to be little consistent relationship between those schools and robbery. For public secondary schools, the presence of a school is clearly associated with more daytime robberies on school days than on non-school days in Chicago, San Francisco and New York, but the relationship is less clear in other cities. In particular, there is no evidence that robberies in block groups with public secondary schools in Louisville or Tucson are higher on school days than on non-school days. Support for H1 and H2 for personal robberies is therefore more mixed than for assaults. 
7.2 Hypothesis 3

Figure 4 shows estimates of the odds ratios for daytime assaults on school days for offenses occurring in public and private places, across the four cities for which location types were available. As for the previous hypotheses, there is little evidence of a relationship between the presence of an elementary school in a block group and the frequency of assaults. The mean probability that the estimate of school-day assaults in public places is greater than the corresponding estimate for school-day assaults in private places in each case is moderately close to $50 \%$. In block groups with public secondary schools, the expected frequency of school-day assaults in public places is between 1.4 and 1.7 times higher than in block groups without schools in Chicago, Los Angeles and New York, but is not higher in Louisville. Figure 5 shows almost identical results for personal robberies, with Louisville again a clear outlier. Overall, the models suggest some support H3 but, as for H1 and H2, there are important differences between cities.

\subsection{Hypothesis 4}

Figure 6 and Figure 7 show estimates of the odds ratios for the relationship between student numbers and assaults in block groups with at least one school. Since the student count parameters were scaled but not mean centered, the odds ratios can be interpreted as the expected change in assaults in a block group with one standard deviation more than zero students, compared to a block group with zero students (student counts are summarized in Table 2).

Figure 6 shows that in most cities more students attending public secondary schools in a block group are associated with more daytime assaults on school days (compared to non-school days), while more students attending public elementary schools is not. A one-standard-deviation increase in students is associated with an increase in assaults of between 1.2 and 1.8 times. The exceptions to this are Kansas City and Louisville, where the secondary-school odds ratios for offenses at school times are similar to those for other periods. Figure 7 shows the corresponding results for personal robberies, with elementary school students again having no consistent relationship while secondary school relationships do, except in Tucson and Louisville.

\section{Discussion}

This study tested four hypotheses based on the routine activities approach to predict the nature of relationships between four types of schools and two types of violent crime in nine cities, controlling for socio-economic variables. Consistent with $\mathrm{H} 1$ in all the cities under study, the frequency of daytime assault was higher in block groups with public secondary schools compared to block groups without schools, but only during the daytime on school days. On 
non-school days the presence of a public secondary school was not associated with more assaults. The same relationship was found for private secondary schools in only two cities, with no relationship in the other seven. Consistent with H2, neither public nor private elementary schools were associated with more assaults.

A similar school-day-only relationship between personal robbery and public secondary schools (consistent with H1) was found in five of the seven cities for which robbery data were analysed. Consistent with $\mathrm{H} 2$, there was no observable relationship between elementary schools and robberies.

Public secondary schools (but not other types of school) in three of the four cities for which H3 could be tested were associated with higher daytime assaults and personal robberies in public places on school days, in comparison to both block groups without schools and in comparison to offences in private places. The findings in these cities were consistent with $\mathrm{H} 3$, but in the fourth city (Louisville) there was no observable relationship.

Finally, in block groups containing schools, more public secondary students (but not more public elementary students) were associated with more assaults and robberies in most cities, consistent with $\mathrm{H} 4$.

Overall, the results for most cities were consistent with the hypotheses: public secondary schools are typically associated with greater violence in the surrounding area, with a larger effect for larger schools. The patterns of that association are consistent with the mechanism outlined by the routine activities approach. There are, however, two important caveats to that general conclusion.

Firstly, the magnitude of the observed relationships between schools and violence varied substantially across cities. The presence of a public secondary school in a block group in San Francisco was associated with a 2.5-times increase in the expected frequency of school-time assaults compared to block groups without schools. However, in Los Angeles such schools were associated with a smaller 1.6-times increase. Similarly, the magnitude of the relationship between a one standard-deviation increase in public secondary school students in a block group and assaults varied between 1.2 and 1.8 .

Secondly, there appears to be some consistency across hypotheses in those cities in which public secondary schools are associated with the greatest increases in violence. San Francisco is associated with the greatest increases in assaults in the models used to test $\mathrm{H} 1, \mathrm{H} 2$ and $\mathrm{H} 4$ (while not being included in the model for H3). Conversely, there is little evidence of any relationship between violence and secondary schools in Louisville across all four hypotheses.

These caveats illustrate the importance of studying relationships between crime and land use in multiple cities. A single-city study using data from San Francisco would have led to very different results compared to an otherwiseidentical study using data from Louisville. This is important for the academic study of crime and place for two reasons. Firstly, it illustrates the importance of considering the choice of city when obtaining data for a single-city study. Many researchers (the present author included) typically start, for practical reasons, by obtaining data from their local police department or an agency 
with which they have personal links. The practicality of this approach may give it an air of inevitability, but researchers should recognize the implications of their choice of city on the results they obtain. The recent availability of open crime data can help researchers understand the limitations of single-city studies by studying multiple cities simultaneously.

The patterns across cities found in this study indicate that relationships vary across cities in consistent ways that themselves require explanation. At present, geocoded crime data are available for only a few cities, excluding the use of city-level predictors such as mayoral policies or police tactics in regression models. However, follow-on exploratory analysis of why relationships between land uses and different crimes exist in some places but not others may well be fruitful.

The between-city variations in results here are also relevant to the use of crime and place research by practitioners. Imagine, for example, a city manager or police chief wishing to use research to understand whether the construction of a new high school in a neighborhood might lead to an increase in violent crime. If the only available study uses data from a single city, it is difficult to know how applicable the results will be elsewhere. If multiple single-city studies exist but the results are contradictory (as with schools and violence), the reader cannot know whether the different results stem from genuine variation between cities or are artifacts produced by varying research methods from one study to another. Multi-city studies provide a useful addition to existing evidence by studying different cities using comparable data and identical methods.

While multi-city studies based on open data allow types of analysis of relationships between crime and place that have not previously been possible, they also have limitations. The first is that researchers only have access to the data that agencies choose to publish. The volume of open data available is increasing rapidly (Barbosa et al. 2014), but much information held by states and municipalities remains unpublished. This means, for example, that it was not possible for the current study to isolate offenses committed by or against school-age children, since for privacy reasons few cities publish any information about the victim in their open crime datasets.

The second limitation of open crime data is that care is required - particularly in model specification - to avoid results being influenced by the methods used by agencies to anonymize open data. In the present study, this meant that it was not possible to test for spatial decay in any relationship between schools and crime because cities typically introduce small errors into published offense co-ordinates to protect victim privacy. As such, this study was restricted to analyses based on areal units, for which Tompson et al. (2014) found that this location obfuscation was unproblematic.

Bearing in mind these limitations, multi-city studies based on open data should be seen as complementary to studies based on internal police-recorded crime data, which are likely to continue to be conducted in single cities. By triangulating both these sources of evidence and others, it is likely to be possible to improve our understanding of the relationships between crimes and places. 


\section{Acknowledgements}

Thank you to Puneet Tiwari of Nottingham Trent University and Jarrod Hadfield of the University of Edinburgh for advice on the methods used in this paper. Any errors are, of course, the sole responsibility of the author. 
10 Figures and Tables

Table 1: Existing studies on violence around schools

\begin{tabular}{|c|c|c|}
\hline Study & Site & $\begin{array}{l}\text { Relationships between local violence and } \\
\text { schools }\end{array}$ \\
\hline $\begin{array}{l}\text { Roncek and } \\
\text { Lobosco (1983) }\end{array}$ & San Diego, CA & $\begin{array}{l}\text { Assault and robbery higher in blocks with } \\
\text { public (but not private) high schools }\end{array}$ \\
\hline $\begin{array}{l}\text { Roncek and } \\
\text { Faggiani (1985) }\end{array}$ & Cleveland, $\mathrm{OH}$ & $\begin{array}{l}\text { Robbery higher in blocks with public or } \\
\text { private high schools, assault higher only in } \\
\text { blocks with public high schools }\end{array}$ \\
\hline Roncek (2000) & Bronx, NY & $\begin{array}{l}\text { Assault higher in blocks with public or } \\
\text { private elementary schools as well as public } \\
\text { (but not private) high schools; robbery } \\
\text { higher in blocks with public high or private } \\
\text { (but not public) elementary schools }\end{array}$ \\
\hline Roman (2003) & $\begin{array}{l}\text { Prince George's } \\
\text { County, MD }\end{array}$ & $\begin{array}{l}\text { Assault higher in blocks with large public or } \\
\text { private middle or high schools, but only at } \\
\text { school times }\end{array}$ \\
\hline $\begin{array}{l}\text { Stucky and } \\
\text { Ottensmann } \\
(2009)\end{array}$ & Indianapolis, IN & $\begin{array}{l}\text { Homicide lower in } 1,000 \text {-foot grid cells with } \\
\text { schools (not differentiated by type) but no } \\
\text { effect for robbery or aggravated assault }\end{array}$ \\
\hline $\begin{array}{l}\text { Murray and } \\
\text { Swatt (2013) }\end{array}$ & Omaha, NE & $\begin{array}{l}\text { Felony assault higher on blocks with public } \\
\text { high (but not middle, or private high) schools }\end{array}$ \\
\hline $\begin{array}{l}\text { Willits, Broidy, } \\
\text { and Denman } \\
(2013)\end{array}$ & Albuquerque, NM & $\begin{array}{l}\text { Aggravated assault (but not robbery) higher } \\
\text { in blocks with high (but not elementary) } \\
\text { schools }\end{array}$ \\
\hline $\begin{array}{l}\text { Haberman and } \\
\text { Ratcliffe }(2015)\end{array}$ & Philadelphia, PA & $\begin{array}{l}\text { Robbery higher in blocks with high schools, } \\
\text { at both school and non-school times }\end{array}$ \\
\hline
\end{tabular}

Table 2: Summary statistics for numeric variables

\begin{tabular}{llrrrr}
\hline City & Variable & Mean & SD & Min & Max \\
\hline Chicago & Assaults & 62 & 68 & 0 & 1,116 \\
& Robberies & 7 & 9 & 0 & 79 \\
& Population & 1,266 & 604 & 127 & 9,364 \\
& Prop. aged 13-19 & 0.12 & 0.07 & 0.00 & 0.55 \\
& Public elementary students & 66 & 163 & 0 & 2,047 \\
& Public secondary students & 74 & 271 & 0 & 4,245 \\
& Prop. commercial land & 0.26 & 0.23 & 0.00 & 1.00 \\
& Ethnic heterogeneity & 0.34 & 0.22 & 0.00 & 0.77 \\
& Population mobility & 0.08 & 0.80 & -1.67 & 3.19 \\
& Concentrated disadvantage & 0.01 & 0.81 & -2.37 & 2.31 \\
\hline \multirow{2}{*}{ Detroit } & Assaults & 49 & 26 & 9 & 232 \\
& Robberies & 5 & 4 & 0 & 31 \\
& Population & 814 & 405 & 58 & 3,268
\end{tabular}


Table 2: Summary statistics for numeric variables (continued)

\begin{tabular}{|c|c|c|c|c|c|}
\hline City & Variable & Mean & $\mathrm{SD}$ & Min & Max \\
\hline & Prop. aged $13-19$ & 0.14 & 0.07 & 0.00 & 0.50 \\
\hline & Public elementary students & 24 & 92 & 0 & 711 \\
\hline & Public secondary students & 37 & 184 & 0 & 2,370 \\
\hline & Prop. commercial land & 0.12 & 0.15 & 0.00 & 0.77 \\
\hline & Ethnic heterogeneity & 0.19 & 0.18 & 0.00 & 0.73 \\
\hline & Population mobility & 0.20 & 0.72 & -1.45 & 3.30 \\
\hline & Concentrated disadvantage & 0.05 & 0.69 & -3.28 & 2.11 \\
\hline \multirow[t]{10}{*}{ Kansas City } & Assaults & 91 & 89 & 0 & 712 \\
\hline & Robberies & - & - & - & - \\
\hline & Population & 1,123 & 637 & 58 & 4,775 \\
\hline & Prop. aged $13-19$ & 0.11 & 0.06 & 0.00 & 0.39 \\
\hline & Public elementary students & 70 & 166 & 0 & 1,105 \\
\hline & Public secondary students & 58 & 251 & 0 & 2,822 \\
\hline & Prop. commercial land & 0.16 & 0.20 & 0.00 & 0.99 \\
\hline & Ethnic heterogeneity & 0.40 & 0.18 & 0.00 & 0.77 \\
\hline & Population mobility & 0.07 & 0.85 & -1.52 & 3.32 \\
\hline & Concentrated disadvantage & 0.01 & 0.83 & -2.70 & 2.63 \\
\hline \multirow[t]{10}{*}{ Los Angeles } & Assaults & 40 & 47 & 0 & 776 \\
\hline & Robberies & 5 & 9 & 0 & 150 \\
\hline & Population & 1,584 & 784 & 197 & 8,905 \\
\hline & Prop. aged $13-19$ & 0.12 & 0.06 & 0.00 & 0.75 \\
\hline & Public elementary students & 82 & 190 & 0 & 1,244 \\
\hline & Public secondary students & 93 & 409 & 0 & 5,338 \\
\hline & Prop. commercial land & 0.12 & 0.15 & 0.00 & 0.87 \\
\hline & Ethnic heterogeneity & 0.46 & 0.18 & 0.00 & 0.78 \\
\hline & Population mobility & 0.06 & 0.80 & -1.63 & 3.91 \\
\hline & Concentrated disadvantage & 0.01 & 0.86 & -2.42 & 2.58 \\
\hline \multirow[t]{10}{*}{ Louisville } & Assaults & 47 & 45 & 1 & 366 \\
\hline & Robberies & 19 & 22 & 0 & 132 \\
\hline & Population & 1,063 & 456 & 160 & 3,998 \\
\hline & Prop. aged $13-19$ & 0.11 & 0.07 & 0.00 & 0.46 \\
\hline & Public elementary students & 59 & 149 & 0 & 635 \\
\hline & Public secondary students & 56 & 260 & 0 & 1,815 \\
\hline & Prop. commercial land & 0.22 & 0.27 & 0.00 & 1.00 \\
\hline & Ethnic heterogeneity & 0.32 & 0.21 & 0.00 & 0.77 \\
\hline & Population mobility & 0.05 & 0.81 & -1.75 & 2.31 \\
\hline & Concentrated disadvantage & 0.01 & 0.83 & -2.38 & 2.30 \\
\hline \multirow[t]{10}{*}{ New York } & Assaults & 20 & 24 & 0 & 364 \\
\hline & Robberies & 4 & 5 & 0 & 47 \\
\hline & Population & 1,383 & 638 & 44 & 9,838 \\
\hline & Prop. aged $13-19$ & 0.11 & 0.06 & 0.00 & 0.64 \\
\hline & Public elementary students & 65 & 197 & 0 & 1,935 \\
\hline & Public secondary students & 71 & 353 & 0 & 6,895 \\
\hline & Prop. commercial land & 0.12 & 0.24 & 0.00 & 1.00 \\
\hline & Ethnic heterogeneity & 0.46 & 0.18 & 0.00 & 0.80 \\
\hline & Population mobility & 0.17 & 0.72 & -1.48 & 3.56 \\
\hline & Concentrated disadvantage & 0.03 & 0.83 & -2.32 & 2.83 \\
\hline \multirow[t]{4}{*}{ San Francisco } & Assaults & 42 & 72 & 1 & 695 \\
\hline & Robberies & 7 & 14 & 0 & 111 \\
\hline & Population & 1,488 & 687 & 120 & 9,541 \\
\hline & Prop. aged 13-19 & 0.07 & 0.06 & 0.00 & 0.65 \\
\hline
\end{tabular}


Table 2: Summary statistics for numeric variables (continued)

\begin{tabular}{llrrrr}
\hline City & Variable & Mean & SD & Min & Max \\
\hline & Public elementary students & 38 & 111 & 0 & 673 \\
& Public secondary students & 56 & 270 & 0 & 2,685 \\
Prop. commercial land & 0.18 & 0.25 & 0.00 & 1.00 \\
Ethnic heterogeneity & 0.56 & 0.12 & 0.08 & 0.78 \\
Population mobility & 0.08 & 0.79 & -1.64 & 3.96 \\
Concentrated disadvantage & 0.00 & 0.80 & -1.63 & 3.51 \\
\hline Tucson & Assaults & 52 & 43 & 0 & 306 \\
& Robberies & 3 & 3 & 0 & 22 \\
& Population & 1,419 & 812 & 304 & 5,717 \\
& Prop. aged 13-19 & 0.12 & 0.07 & 0.00 & 0.62 \\
Public elementary students & 80 & 176 & 0 & 1,096 \\
& Public secondary students & 112 & 378 & 0 & 3,591 \\
Prop. commercial land & 0.23 & 0.21 & 0.00 & 1.00 \\
& Ethnic heterogeneity & 0.46 & 0.15 & 0.04 & 0.75 \\
Population mobility & 0.06 & 0.89 & -1.58 & 2.75 \\
Concentrated disadvantage & 0.00 & 0.82 & -1.78 & 2.18 \\
\hline Virginia Beach & Assaults & 32 & 33 & 0 & 284 \\
& Robberies & - & - & - & - \\
& Population & 1,501 & 725 & 451 & 4,456 \\
& Prop. aged 13-19 & 0.12 & 0.05 & 0.00 & 0.33 \\
Public elementary students & 90 & 224 & 0 & 1,293 \\
Public secondary students & 126 & 474 & 0 & 3,776 \\
Prop. commercial land & 0.12 & 0.18 & 0.00 & 1.00 \\
& Ethnic heterogeneity & 0.47 & 0.20 & 0.00 & 0.76 \\
Population mobility & 0.03 & 0.91 & -1.30 & 3.22 \\
Concentrated disadvantage & 0.00 & 0.74 & -1.68 & 2.42 \\
\hline & & & &
\end{tabular}

Table 3: Count of blockgroups with and without schools

\begin{tabular}{lrrlrr}
\hline & \multicolumn{4}{l}{ Block groups with one or more schools } \\
\cline { 3 - 6 } City & $\begin{array}{l}\text { Block } \\
\text { groups }\end{array}$ & $\begin{array}{l}\text { private } \\
\text { elementary }\end{array}$ & $\begin{array}{l}\text { private } \\
\text { secondary }\end{array}$ & $\begin{array}{l}\text { public } \\
\text { elementary }\end{array}$ & $\begin{array}{l}\text { public } \\
\text { secondary }\end{array}$ \\
\hline Chicago & 2,049 & 155 & 145 & 400 & 443 \\
Detroit & 775 & 12 & 10 & 59 & 68 \\
Kansas City & 410 & 26 & 28 & 79 & 37 \\
Los Angeles & 2,421 & 208 & 167 & 452 & 215 \\
Louisville & 225 & 23 & 20 & 33 & 16 \\
New York & 5,833 & 379 & 409 & 786 & 539 \\
San Francisco & 554 & 64 & 63 & 71 & 42 \\
Tucson & 356 & 24 & 17 & 77 & 71 \\
Virginia Beach & 296 & 32 & 12 & 49 & 24 \\
\hline
\end{tabular}


Figure 1: Schools typically take up most or all of a census block

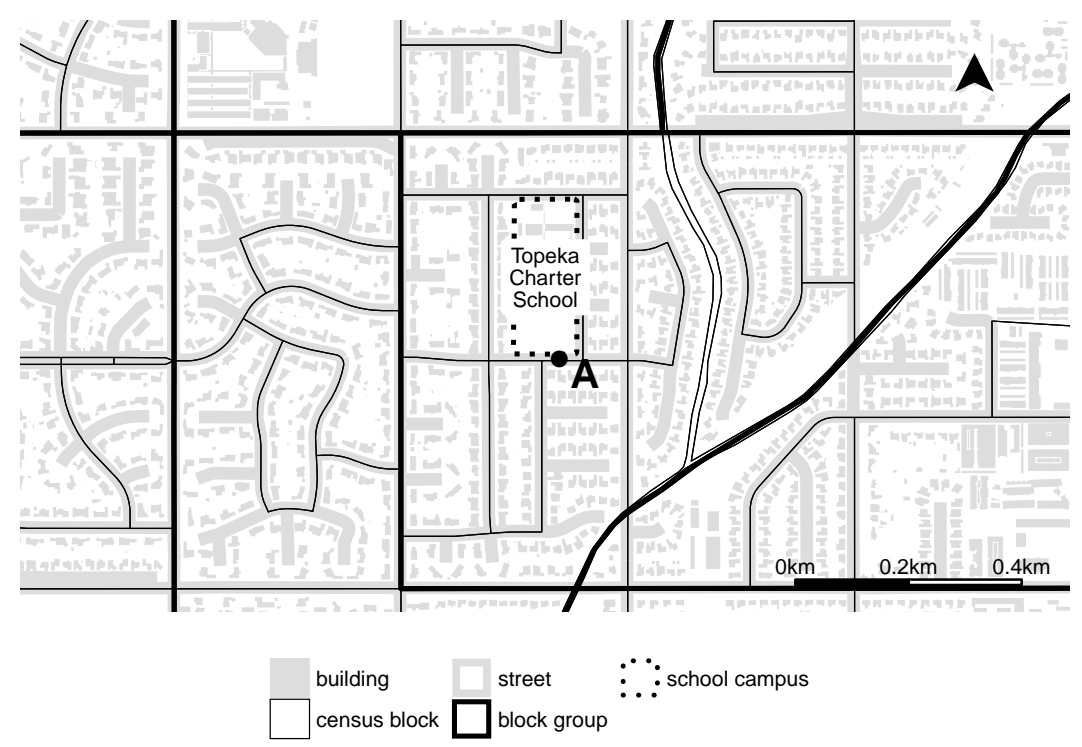

Map data $\odot$ openstreetmap.org contributors 
Figure 2: Estimates of relationships between schools and assaults by time period

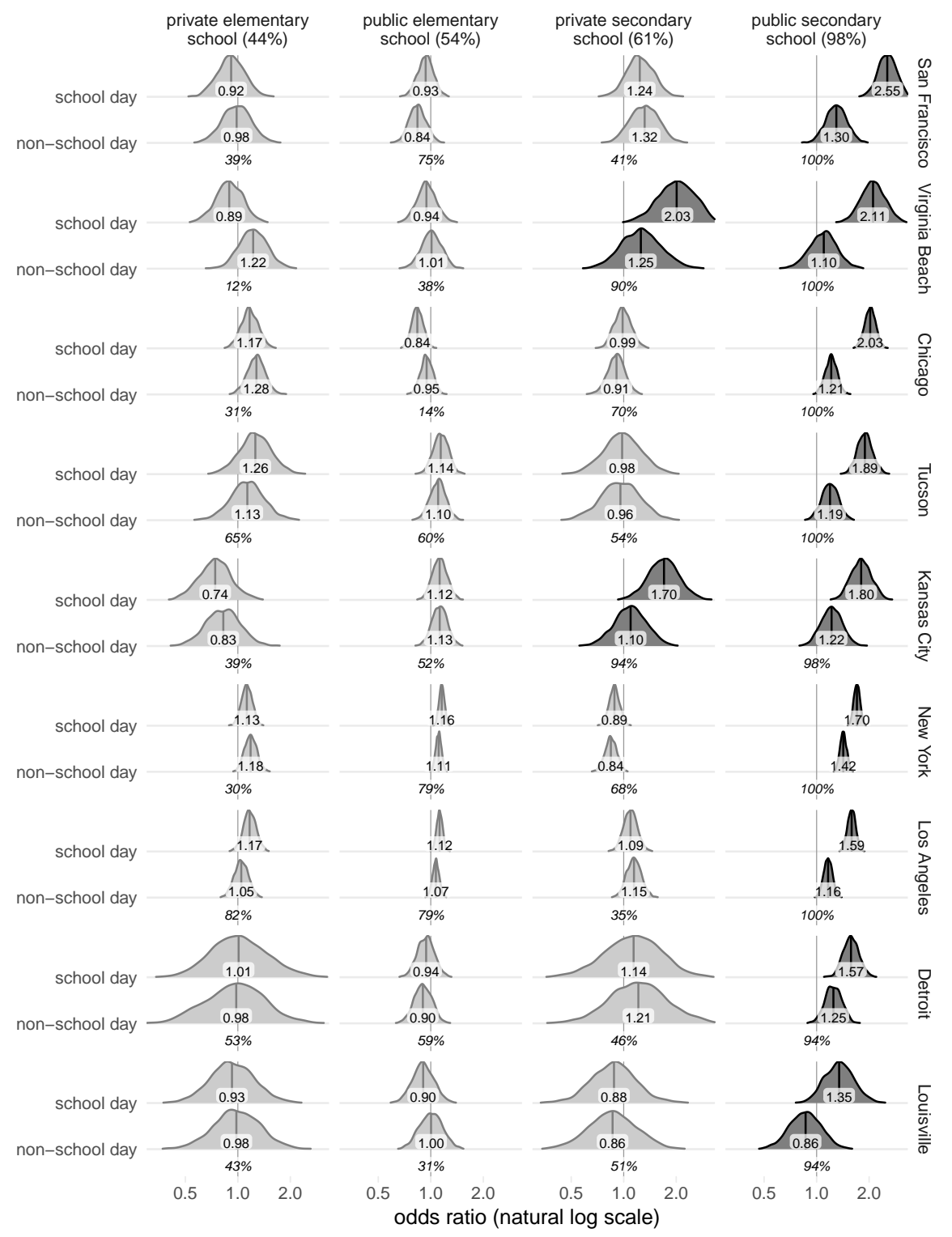

$>90 \%$ probability that odds ratio for school day is greater than odds ratio for non-school day 
Figure 3: Estimates of relationships between schools and personal robberies by time period

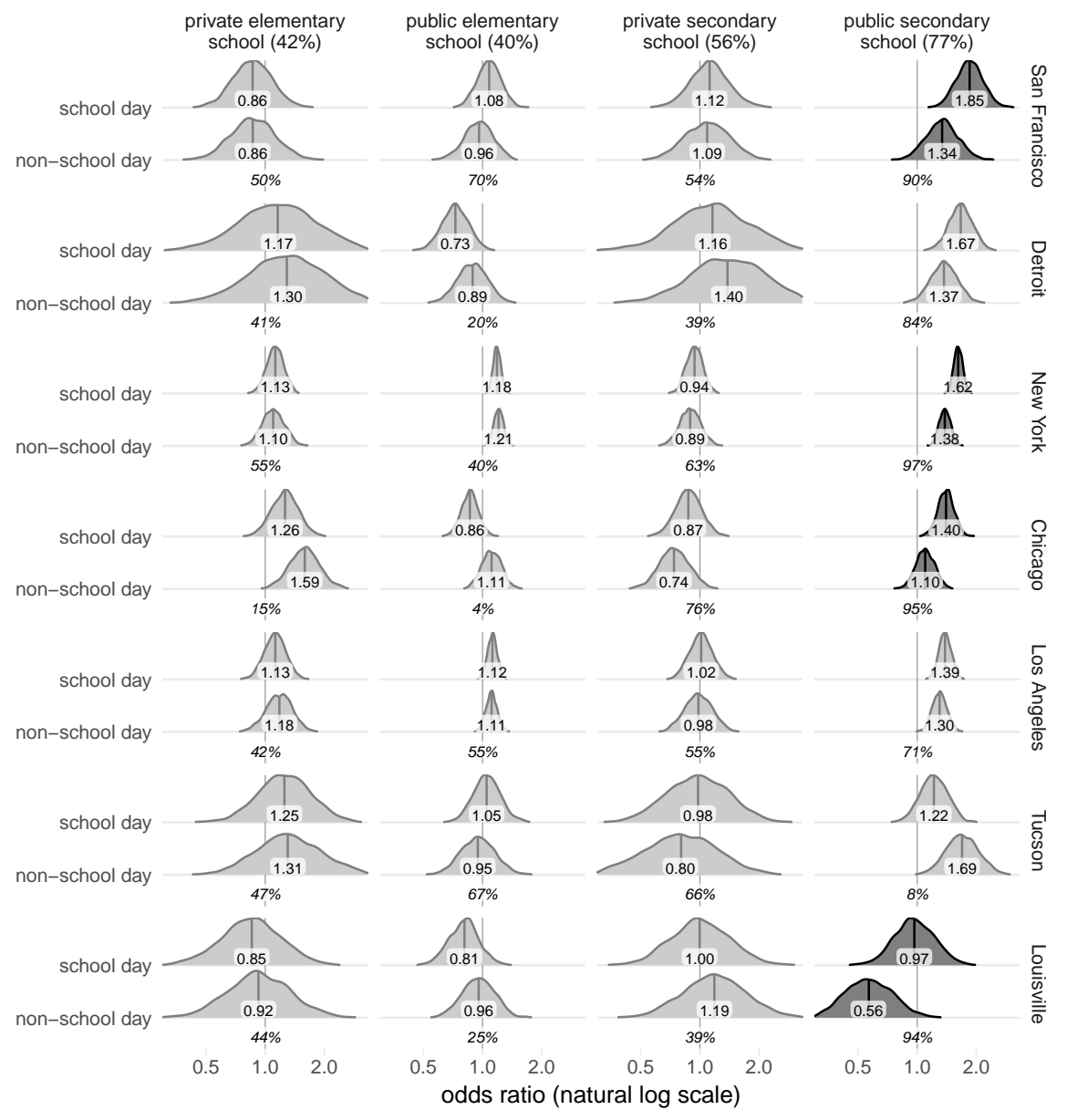

$>90 \%$ probability that odds ratio for school day is greater than odds ratio for non-school day 
Figure 4: Estimates of relationships between schools and assaults by location type

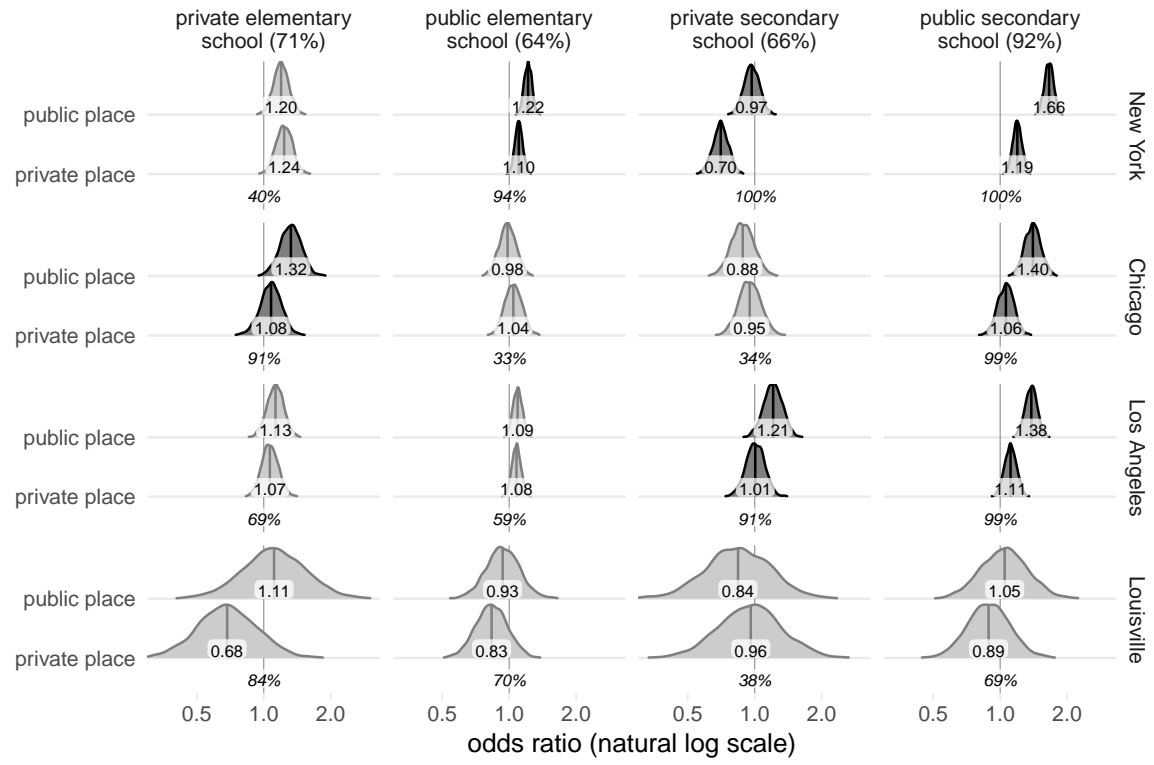

$>90 \%$ probability that odds ratio for public place is greater than odds ratio for private place 
Figure 5: Estimates of relationships between schools and personal robberies by location type

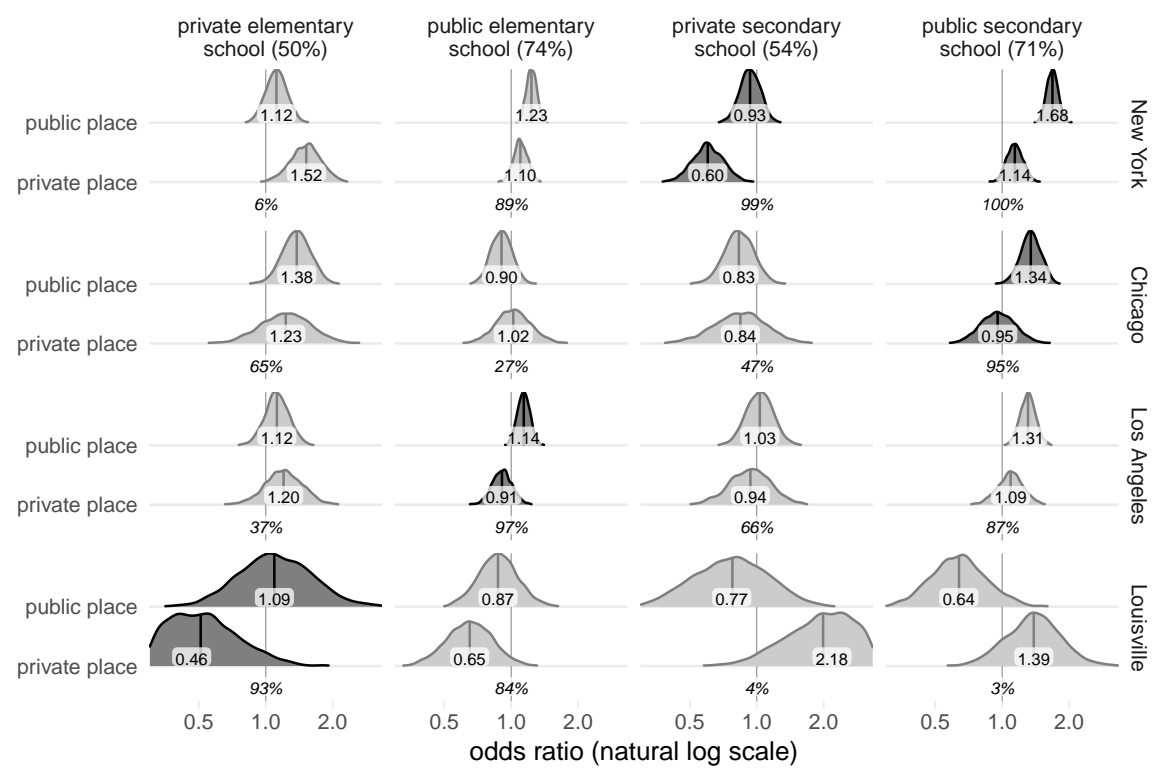

$>90 \%$ probability that odds ratio for public place is greater than odds ratio for private place 
Figure 6: Estimates of relationships between student numbers and assaults by time period

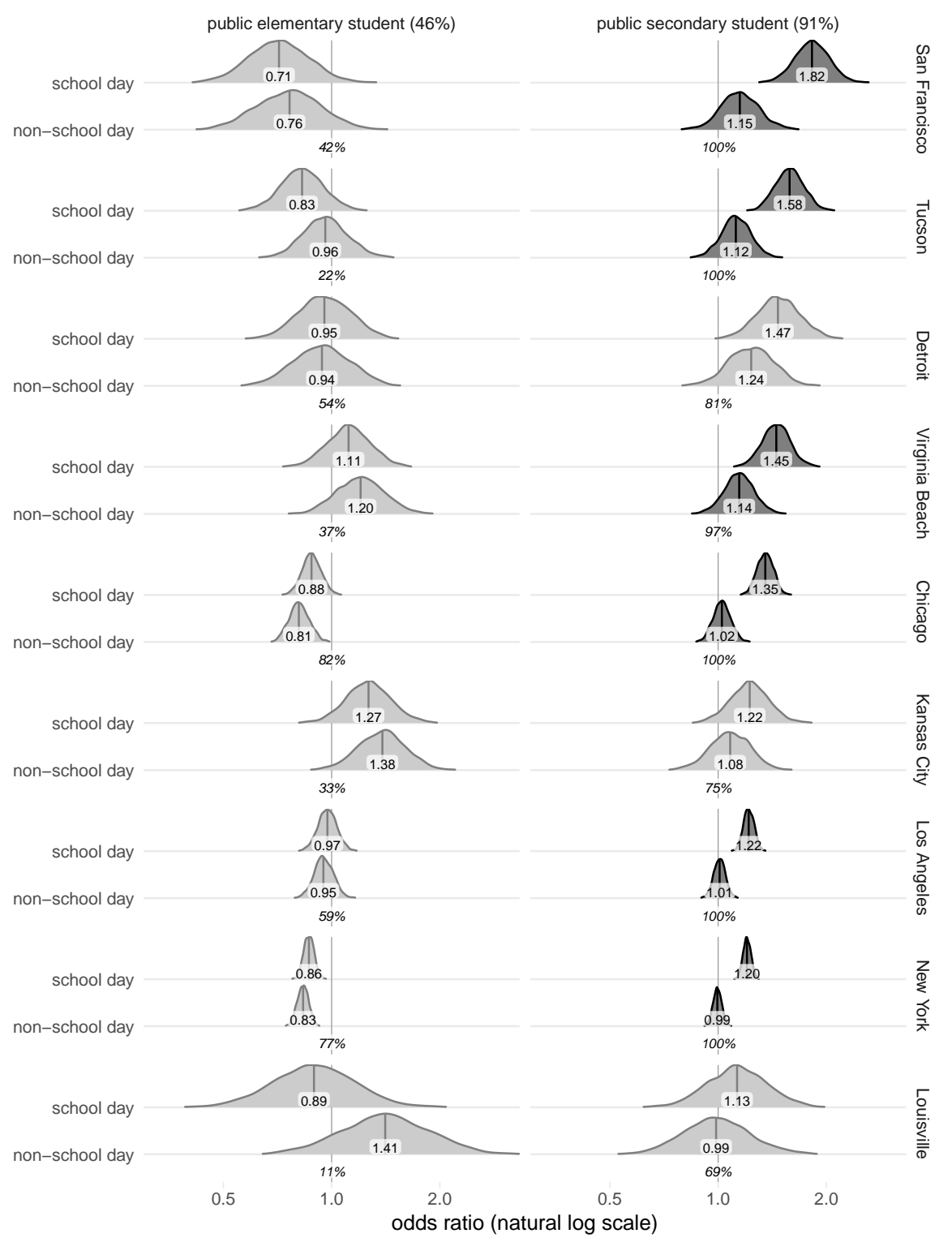

$>90 \%$ probability that odds ratio for school day is greater than odds ratio for non-school day 
Figure 7: Estimates of relationships between student numbers and personal robberies by time period

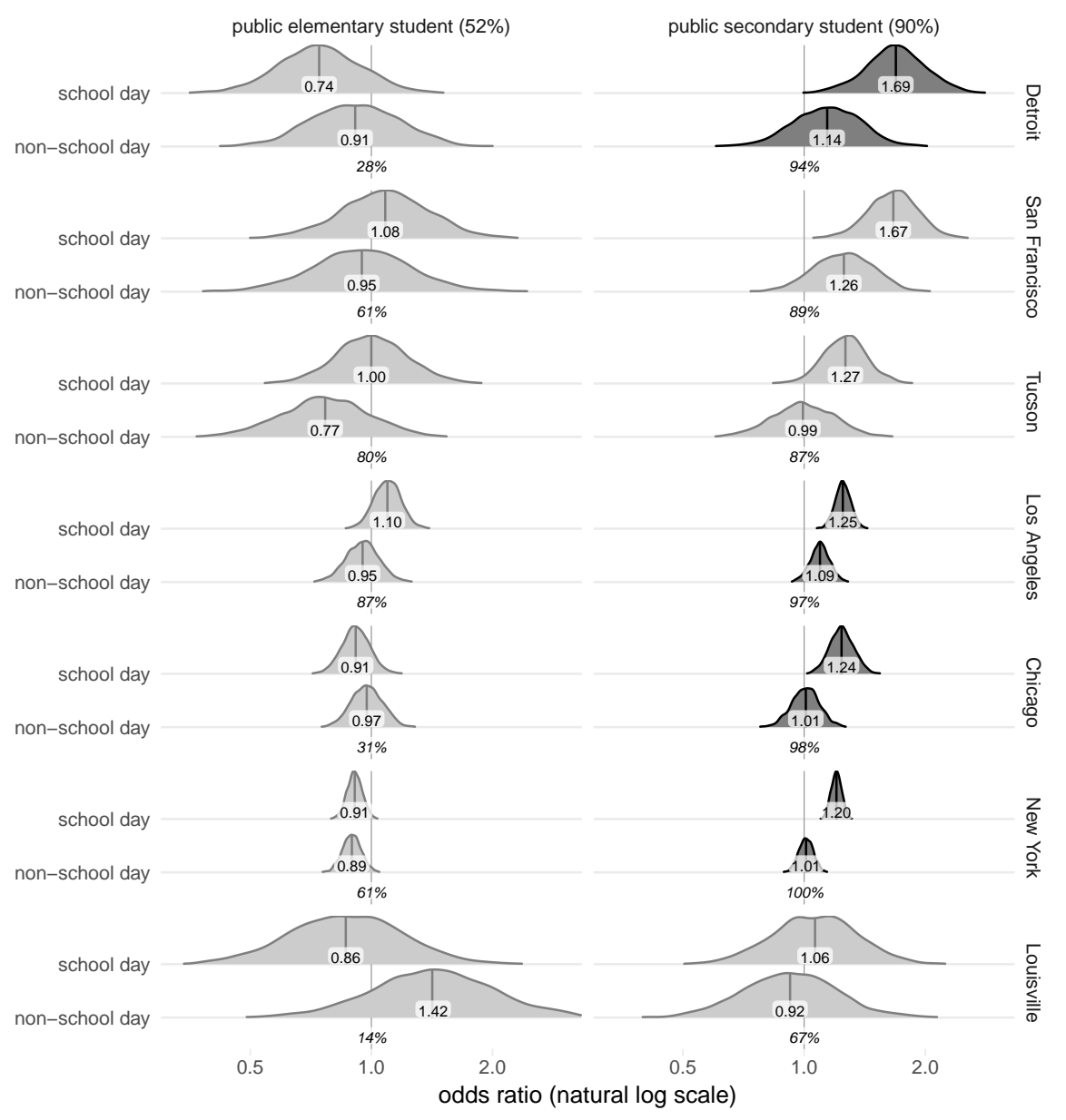

$>90 \%$ probability that odds ratio for school day is greater than odds ratio for non-school day 


\section{A Appendix}

In the review of existing literature above, this study reports odds ratios for previous studies as measures of effect size for the relationship between public high schools and assaults. Most studies reported multiple models, so the data used for this purpose are reproduced here to allow readers to understand the data being used for this comparison.

Roncek (2000), Willits, Broidy, and Denman (2013) and Haberman and Ratcliffe (2015) reported odds ratios from negative-binomial regression models, while Roncek and Lobosco (1983) and Murray and Swatt (2013) reported co-efficients (b) from ordinary least squares models. To produce comparable effect sizes, the unstandardized $b$ co-efficients were converted to odds ratios using the approximate method outlined by Lüdecke (2018) and implemented in the effects package in $\mathrm{R}$ version 3.5 ( $\mathrm{R}$ Core Team 2018). This method uses the $b$ coefficient, the standard deviation of the dependent variable and the number of blocks both with and without schools included in the model. Effect size for the results reported by Roncek and Faggiani (1985) could not be calculated because that study did not publish variable standard deviations. The results reported by Roman (2003) are not directly comparable because that study investigated the effect of distance from each block to the nearest school, rather than the presence of absence of a school on the block itself. Similarly, Stucky and Ottensmann (2009) used 1,000-foot grid cells as the unit of analysis, so the results are not directly comparable.

\begin{tabular}{lrrrr}
\hline Source & $\begin{array}{l}\text { Odds } \\
\text { ratio }\end{array}$ & $b$ & SD & $\begin{array}{r}\text { Blocks with/ } \\
\text { without school }\end{array}$ \\
\hline $\begin{array}{l}\text { Roncek and Lobosco (1983), Table } \\
4 \text { (assault) }\end{array}$ & 1.46 & 0.17 & 0.81 & $131 / 4455$ \\
$\begin{array}{l}\text { Roncek (2000), Table 12.2 (assault) } \\
\text { Murray and Swatt (2013), Table 2 } \\
\text { felonious assault) }\end{array}$ & 1.08 & & & \\
$\begin{array}{l}\text { Willits, Broidy, and Denman } \\
\text { (2013), Table 3 (aggravated }\end{array}$ & 1.05 & 0.03 & 1.13 & $161 / 7678$ \\
$\begin{array}{l}\text { assault) } \\
\text { Haberman and Ratcliffe (2015), }\end{array}$ & & & & \\
Table 2 (daytime assault) & 2.07 & & & \\
\hline
\end{tabular}

Anselin, L, and D A Griffith. 1988. "Do Spatial Effects Really Matter in Regression Analysis?" Papers in Regional Science 65 (1): 11-34. doi:10.1111/j.1435-5597.1988.tb01155.x.

Ashby, M P J. 2018. "Studying Crime and Place with the Crime Open Database." Research Data Journal for the Humanities and Social Sciences.

Austin, S. Bryn, Steven J. Melly, Brisa N. Sanchez, Aarti Patel, Stephen Buka, and Steven L. Gortmaker. 2005. "Clustering of Fast-Food Restaurants Around Schools: A Novel 
Application of Spatial Statistics to the Study of Food Environments." American Journal of Public Health 95 (9): 1575-81. doi:10.2105/AJPH.2004.056341.

Bacon, S, R Paternoster, and R Brame. 2009. "Understanding the Relationship Between Onset Age and Subsequent Offending During Adolescence." Journal of Youth and Adolescence 38 (3): 301-11. doi:10.1007/s10964-008-9322-7.

Barbosa, Luciano, Kien Pham, Claudio Silva, Marcos R Vieira, and Juliana Freire. 2014. "Structured Open Urban Data: Understanding the Landscape." Big Data 2 (3): 144-54. doi:10.1089/big.2014.0020.

Bartoń, Kamil. 2018. MuMIn: Multi-Model Inference. https://CRAN.R-project.org/ package=MuMIn.

Centers for Disease Control and Prevention. 2014. "Web-Based Injury Statistics Query and Reporting System (WISQARS)." http://www.cdc.gov/injury.

Chainey, S, and J H Ratcliffe. 2005. GIS and Crime Mapping. Chichester: Wiley.

Cohen, L E, and M Felson. 1979. "Social Change and Crime Rate Trends: A Routine Activity Approach." American Sociological Review 44 (4): 588-608.

Cunradi, Carol B, Christina Mair, William Ponicki, and Lillian Remer. 2011. "Alcohol Outlets, Neighborhood Characteristics, and Intimate Partner Violence: Ecological Analysis of a California City." Journal of Urban Health 88 (2): 191-200. doi:10.1007/s11524-0119549-6.

Eck, J E, and T D Madensen. 2015. "Meaningfully and Artfully Reinterpreting Crime for Useful Science: An Essay on the Value of Building with Simple Theory." In The Criminal 
Act: The Role and Influence of Routine Activity Theory, edited by M A Andresen and G Farrell, 5-18. Basingstoke, Hampshire: Palgrave Macmillan. doi:10.1057/9781137391322.0006.

Gelman, Andrew, and Donald B. Rubin. 1992. "Inference from Iterative Simulation Using Multiple Sequences." Statistical Science 7 (4): 457-72. doi:10.1214/ss/1177011136.

Gerell, M. 2018. "Quantifying the Geographical (Un)reliability of Police Data." Nordisk Politiforskning 5 (2). https://www.idunn.no/nordisk_politiforskning/2018/02/quantifying_ the_geographical_unreliability_of_police_data.

Gracia, Enrique, Antonio López-Quílez, Miriam Marco, Silvia Lladosa, and Marisol Lila. 2015. "The Spatial Epidemiology of Intimate Partner Violence: Do Neighborhoods Matter?" American Journal of Epidemiology 182 (1): 58-66. doi:10.1093/aje/kwv016.

Haberman, C P, and J H Ratcliffe. 2015. "Testing for Temporally Differentiated Relationships Among Potentially Criminogenic Places and Census Block Street Robbery Counts." Criminology 53 (3): 457-83. doi:10.1111/1745-9125.12076.

Hadfield, Jarrod D. 2010. "MCMCglmm: MCMC Methods for Multi-Response GLMMs in R." Journal of Statistical Software 33 (2): 1-22. doi:10.1002/ana.22635.

Harrell, E. 2012. Violent Victimization Committed by Strangers, 1993-2010. Bureau of Justice Statistic Special Report. Washington, DC: US Department of Justice. https: //www.bjs.gov/content/pub/pdf/vvcs9310.pdf.

Law, Jane, Matthew Quick, and Ping Chan. 2014. "Bayesian Spatio-Temporal Modeling for Analysing Local Patterns of Crime Over Time at the Small-Area Level." Journal of Quantitative Criminology 30 (1): 57-78. doi:10.1007/s10940-013-9194-1.

Li, G, R Haining, S Richardson, and N Best. 2014. "Space-Time Variability in Burglary Risk: A Bayesian Spatio-Temporal Modelling Approach." Spatial Statistics 9 (C): 180-91. doi:10.1016/j.spasta.2014.03.006

Lüdecke, Daniel. 2018. Esc: Effect Size Computation for Meta Analysis. https://CRAN . R-project.org/package=esc.

Murray, R K, and M L Swatt. 2013. "Disaggregating the Relationship Between Schools and Crime: A Spatial Analysis." Crime and Delinquency 59 (2): 163-90. doi:10.1177/0011128709348438.

National Center for Education Statistics. 2016a. "Common Core of Data." https:// nces.ed.gov/ccd/.

2016b. "Private School Universe Survey." https://nces.ed.gov/surveys/pss/.

National Council on Teacher Quality. 2018. https://www.nctq.org/contract-database.

Plummer, Martyn, Nicky Best, Kate Cowles, and Karen Vines. 2006. "CODA: Convergence Diagnosis and Output Analysis for Mcmc." R News 6 (1): 7-11. https://journal.rproject.org/archive/.

Pridemore, William Alex, Matthew C Makel, and Jonathan A Plucker. 2018. "Replication in Criminology and the Social Sciences." Annual Review of Criminology 1: 19-38. doi:10.1146/annurev-criminol.

R Core Team. 2018. R: A Language and Environment for Statistical Computing. Vienna, Austria: R Foundation for Statistical Computing. https://www.R-project.org/.

Roman, C G. 2003. "Schools as Generators of Crime: Routine Activities and the Sociology of Place." PhD thesis, American University.

Roncek, D W. 2000. "Schools and Crime." In Analyzing Crime Patterns: Frontiers of Practice, 153-65. Thousand Oaks: Sage.

Roncek, D W, and D Faggiani. 1985. "High Schools and Crime: A Replication." The Sociological Quarterly 26 (4): 491-505.

Roncek, D W, and A Lobosco. 1983. "The Effect of High Schools on Crime in Their Neighborhoods." Social Science Quarterly 64 (3): 598-613.

Sparks, Corey S. 2011. "Violent Crime in San Antonio, Texas: An Application of Spatial Epidemiological Methods." Spatial and Spatio-Temporal Epidemiology 2 (4). Elsevier Ltd: 301-9. doi:10.1016/j.sste.2011.10.001.

Spiegelhalter, David J, Nicola G Best, Bradley P Carlin, and Angelika van der Linde. 2002. "Bayesian Measures of Model Complexity and Fit." Journal of the Royal Statistical Society: Series B (Statistical Methodology) 64 (4): 583-639. doi:10.1111/1467-9868.00353.

Stucky, T D, and J R Ottensmann. 2009. "Land Use and Violent Crime." Criminology 47 (4): 1223-64. doi:10.1111/j.1745-9125.2009.00174.x.

Telesca, Donatello, Elena A Erosheva, Derek A Kreager, and Ross L Matsueda. 2012. "Modeling Criminal Careers as Departures from a Unimodal Population Age-Crime Curve: 
The Case of Marijuana Use." Journal of the American Statistical Association 107 (500): 1427-40. doi:10.1080/01621459.2012.716328.

Tompson, L, S D Johnson, M P J Ashby, C Perkins, and P Edwards. 2014. "UK Open Source Crime Data: Accuracy and Possibilities for Research." Cartography and Geographic Information Science 42 (2): 97-111. doi:10.1080/15230406.2014.972456.

US Census Bureau. 2008. 2010 Participant Statistical Areas Program. Washington, DC: US Department of Commerce. https://www2. census .gov/geo/pdfs/partnerships/psap2010_ part_info.pdf.

Walker, Kyle. 2018a. tidycensus: Load US Census Boundary and Attribute Data as 'Tidyverse' and 'Sf'-Ready Data Frames. https: //CRAN.R-project.org/package=tidycensus. - 2018b. tigris: Load Census TIGER/Line Shapefiles. https://CRAN.R-project. org/package=tigris

Wilcox, P, and J E Eck. 2011. "Criminology of the Unpopular: Implications for Policy Aimed at Payday Lending Facilities." Criminology and Public Policy 10 (2): 473-82. doi:10.1111/j.1745-9133.2011.00721.x.

Willits, D, L Broidy, and K Denman. 2013. "Schools, Neighborhood Risk Factors, and Crime." Crime and Delinquency 59 (2): 292-315. doi:10.1177/0011128712470991.

Young, Jacob T.N. 2011. "How Do They 'End up Together'? A Social Network Analysis of Self-Control, Homophily, and Adolescent Relationships." Journal of Quantitative Criminology 27 (3): 251-73. doi:10.1007/s10940-010-9105-7.

Zhu, Li, Dennis M Gorman, and Scott Horel. 2006. "Hierarchical Bayesian Spatial Models for Alcohol Availability, Drug 'Hot Spots' and Violent Crime." International Journal of Health Geographics 5: 1-12. doi:10.1186/1476-072X-5-54. 